\title{
Validation study of a software for proprioceptive evaluation
}

\section{Estudo de validação de um programa de computador para avaliação proprioceptiva}

\author{
iDenrique Franco Ferreira ${ }^{1}$, (iD Leonardo César Carvalho ${ }^{1}$, (iD Paulo Alexandre Bressan ${ }^{1}$, (iD Renato Aparecido de Souza ${ }^{1,2}$, \\ iD Adriano Prado Simão ${ }^{1}$, (D) Denise Hollanda lunes ${ }^{1}$
}

\footnotetext{
1 Universidade Federal de Alfenas - UNIFAL 2 Instituto Federal de Educação, Ciência e Tecnologia do Sul de Minas - IFSULDEMINAS

Corresponding

Denise Hollanda lunes

E-mail: deniseiunes@unifal-mg.edu.br
}

Submitted: February 2, 2021

Accepted: March 26, 2021

How to cite

Ferreira HF, Carvalho LC, Bressan PA, Souza RA, Simão $A P$, lunes $D H$. Validation study of a software for proprioceptive evaluation. Acta Fisiatr. 2021;28(1):15-21

\section{Funding}

Coordenação de Aperfeiçoamento de Pessoal de Nível Superior - Brasil (CAPES) - Finance Code 001

10.11606/issn.2317-0190.v28i1a181737

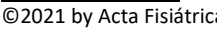

This work is licensed under a Creative Commons Attribution 4.0 International

\begin{abstract}
Objective: To validate the PhisioPlay software for proprioceptive evaluation of the shoulder joint based on the data obtained by isokinetic dynamometry equipment. Methods: Thirty-one individuals constituted a single group for proprioceptive evaluation of both shoulder joints by means of joint position sense (JPS). The testing protocol of PhisioPlay consisted of the abduction movement of the shoulder to the target angles of $45^{\circ}$ and $90^{\circ}$ and the maintenance of these positions for 30 seconds. In the isokinetic dynamometer, the test was performed using its proprioceptive evaluation protocol for the same movement, target angles, and maintenance time established for the previous test. Results: For the $90^{\circ}$ variables, statistical analysis pointed to agreement for the dominant limb in relation to the mean angulation and the absolute difference and for the non-dominant limb in relation to the absolute difference. The results of mean comparisons of the absolute differences via the Wilcoxon Test corroborate the literature regarding the behavior of the JPS considering joint amplitude, lateral dominance, and greater or lesser torque affecting the joint. Reliability and sensitivity measures also strengthen the conclusions. Conclusion: The results point to the construct validity of the PhisioPlay software for evaluating the JPS of the shoulder joint at $45^{\circ}$ and $90^{\circ}$ and suggest that the JPS is more influenced by the angle of the joint during the motor task than by the lateral dominance.
\end{abstract}

Keywords: Shoulder Joint, Proprioception, Software, Rehabilitation

\section{RESUMO}

Objetivo: Validar do software PhisioPlay para avaliação proprioceptiva da articulação do ombro realizando movimento de abdução a 45 e 90ํ utilizando os dados obtidos por um equipamento de dinamometria isocinética. Métodos: Trinta e um indivíduos compuseram um único grupo de avaliação da propriocepção pelo senso de posição articular (SPA) do ombro. O protocolo de teste no PhisioPlay consistiu no movimento de abdução do ombro para o ângulo alvo de $45^{\circ}$ e $90^{\circ}$ e sua manutenção por 30 segundos. No dinamômetro isocinético o teste foi realizado utilizando seu protocolo de avaliação proprioceptiva para o mesmo movimento, ângulos alvo e tempo de manutenção no ângulo alvo estabelecidos para o teste anterior. Resultados: Para as variáveis de $90^{\circ}$ foi observada concordância moderada para o membro dominante em relação à angulação média e à diferença absoluta, e para o membro não dominante em relação à diferença absoluta. O teste de Wilcoxon ao comparar os valores dos erros absolutos em relação ao ângulo alvo obtidos pelo PhisioPlay corroboram com a literatura sobre o comportamento do SPA observando amplitude articular, lateralidade e maior ou menor torque incidindo sobre a articulação. Medidas de confiabilidade e sensibilidade também reforçaram este comportamento. Conclusão: Os resultados apontam para validade de construto do software PhisioPlay para a avaliação do SPA da articulação do ombro a $45^{\circ}$ e $90^{\circ}$ e sugerem que o SPA é mais influenciado pela angulação da articulação durante a tarefa motora do que pela dominância lateral.

Palavras-chaves: Articulação do Ombro, Propriocepção, Software, Reabilitação 


\section{INTRODUCTION}

Proprioception, alongside tactile, temperature, and pain, is considered a sensation of the somatosensory system. ${ }^{1}$ It is characterized by afferent information regarding joint position (ability to perceive the orientation of a joint in space), kinesthesia (sensation of active or passive movement), sense of force (perception of tension generated on a joint), and sense of change in speed. ${ }^{2}$ That is, mechanical stimuli are converted into neural stimuli by the afferent pathways of the central nervous system. ${ }^{3,4}$

Joint position sense (JPS) is the most evaluated proprioceptive feature in clinical trials and offers the most possibilities for application in clinical practice. The evaluation consists of observing the precision of joint repositioning at a predetermined target angle and calculating the error in degrees. 4,5,6 Goniometers, inclinometers, isokinetic dynamometers, and image and movement analysis systems, among other types of equipment developed by the researchers themselves, are used to assess JPS. However, the accuracy of some equipment, as well as the reproducibility of its results, can be questioned. Accurate instruments, such as isokinetic dynamometers, are expensive, difficult to transport, and require a lot of time in the preparation and execution of tests. In addition, they require trained evaluators to avoid error., ${ }^{5,6}$

Clark et al. ${ }^{7}$ highlight the possibility of developing new technologies using smartphones (which have accelerometers and gyroscopes), devices with camera systems, such as Kinect ${ }^{\circledR}$ (Nintendo Co. Ltd. Kyoto, Japan), and other video- and imagebased technologies.

Existing technologies that capture images, such as Kinect ${ }^{\circledR}$, can help to advance and facilitate the development of these new tools. ${ }^{8}$ Kinect $^{\circledR}$ is a device that captures movement by means of a camera, motion sensors, and infrared emitters, and it has enabled the development of software that also recognizes joints of the human body, making it possible to track all body movements as well as their amplitude. ${ }^{9,10}$

Recently, at the Federal University of Alfenas (UNIFAL-MG), the PhisioPlay software was developed to assess shoulder joint function; this software may be a low-cost and easy-to-use alternative for assessing proprioception. ${ }^{11-13}$ PhisioPlay has a simple interface and, installed on a desktop computer or laptop connected to a Kinect ${ }^{\circledR}$ device, enables the evaluation of the angular range of movement as well as the time spent by the patient to achieve the proposed angulation.

Proprioception is an important factor in the rehabilitation process of musculoskeletal injuries and in preventing the recurrence of these injuries. ${ }^{14-16}$ In addition, proprioception acts as an important mechanism for transmitting sensory information with the potential for neural plasticity, the relationship between perception and sensory transmission being well-accepted, and the expression of representations in primary regions of the brain responsible for the sensorimotor system. ${ }^{4,17}$

\section{OBJECTIVE}

The aim of this study was to validate the PhisioPlay software for proprioceptive evaluation of the shoulder joint based on data obtained by isokinetic dynamometry equipment.

\section{METHODS}

This is a methodological study with a quantitative approach for the validation of the PhisioPlay software carried out between September 2019 and September 2020. The research was approved by the Research Ethics Committee of the Federal University of Alfenas (CAAE 03508818.0.0000.5142, no. 3.156.299). All volunteers signed the informed consent form.

Thirty-one university students recruited from a higher education institution through classroom invitations constituted a single group to assess the shoulder JPS.

Youths of both genders and of at least 18 years of age who were physically active as assessed by the International Physical Activity Questionnaire (IPAQ) ${ }^{18}$ and willing to participate in the study were included. Volunteers who reported pain, edema, injuries, or fractures in the upper limbs or who received any score on the Brazilian version of the Shoulder Pain and Disability Index (SPADI) ${ }^{19}$ were excluded.

All volunteers had the abduction movement JPS of both their shoulders evaluated using two devices: PhisioPlay, and a Biodex System 4 Pro isokinetic dynamometer (Biodex, Shirley, NY, USA). The order in which the instruments were used, the sequence of the test, and the target angles were randomized.

The acquisition of data by PhisioPlay occurred with the volunteer positioned in orthostatism in front of the Kinect ${ }^{\circledast}$ device connected to a laptop with the PhisioPlay software installed. On the laptop screen, the participants could see their image and observe the movement trajectory with numerical indication of the angular position of the tested limb during the entire abduction movement of the shoulder.

Each shoulder was assessed six times followed by an interval of thirty seconds between each test. The first test of the protocol always included visual feedback for the purpose of memorizing the angular position, following which the volunteers were blindfolded. When blindfolded, volunteers received verbal instructions to start and finish the test. The software was programmed with the indication of the member to be tested (left or right), the duration of the session (30 seconds), the frequency of recording of data obtained in the output file ( 0.1 second), and the target angle $\left(45^{\circ}\right.$ or $\left.90^{\circ}\right)$.

A Biodex System 4 Pro isokinetic dynamometer (Shirley, NY, USA) was used to assess the JPS of volunteers' shoulders via the proprioceptive test protocol of the equipment's software. The test protocol consisted of the subjected being seated and blindfolded and holding the device's stop button (with the contralateral hand), their body stabilized on the chair with the hip strap.

The strap that crosses the trunk over the shoulder was used only on the contralateral side so that there was no stimulation of mechanoceptors in the region, which would influence the perception of angulation. The isokinetic dynamometer was calibrated daily before the first test of the day. The protocol defined for the test was bilateral, active mode, with a single target angular position $\left(45^{\circ}\right.$ or $\left.90^{\circ}\right)$ to be reached from $15^{\circ}$, which would allow the subject to hold the bar coupled to the rotation axis of the equipment, with the limb to be tested extended and relaxed.

Three repetitions were performed at the maximum angular speed allowed by the device (360\%/s). Limits of range of motion were set on the isokinetic dynamometer ranging from $0^{\circ}$ to 
$180^{\circ}$, allowing the subject total freedom of amplitude and speed of movement to reach the target angle.

PhisioPlay generates a spreadsheet as an output file in Microsoft Office Excel (2013) format. The information contained in this spreadsheet shows the position of the joint tested every 0.1 second. Although the spreadsheet generated contained data collected from zero to 30 seconds, we standardized that we would only consider angular positioning data from six to ten seconds of testing.

This decision was made to avoid possible biases, such as those caused by the volunteer delaying the start of the movement of positioning the joint, which would compromise the initial values, or muscle fatigue, which would influence the final values of the tests.

Considering the angular values obtained from the sixth to the tenth second, the angular mean obtained in this interval was calculated, as was the difference between the mean angular value and the target angle for all spreadsheets generated by PhisioPlay. The isokinetic dynamometer generates an output file containing the mean angle of the three sets of each shoulder and their differences from the target angle.

A pilot study was previously conducted with ten individuals who were evaluated on both Phisioplay and isokinetic dynamometer. Then, the sample size was calculated by G*Power version 3.1.9.6 (Franz Faul, Universität Kiel, Germany) comparing the target angle means by the Wilcoxon-MannWhitney test of the evaluations performed. The sample size calculation indicated 24 individuals (power: 0.95).

For statistical analysis, the Statistical Package for the Social Sciences (SPSS) (IBM Corp. Chicago) software version 20.0 for Windows was used. The normality of the data was verified by the Kolmogorov-Smirnov test. The reliability was calculated by the intraclass correlation coefficient (ICC) (type 2, 3), interpreted as follows: less than 0.40 indicates low reliability; between 0.40 and 0.75 , moderate; between 0.75 and 0.90 , substantial; and greater than 0.90 , excellent. ${ }^{20}$ The data was considered significant at and above the level of $95 \%(p<0.05)$.
The Wilcoxon test for mean comparisons was applied to observe the JPS behavior regarding angulation, instruments, and limb dominance. ${ }^{21}$ The standard error of measurement (SEM) was calculated. Just as the ICC is a measure of reliability, ${ }^{14}$ the SEM involves the calculation of the variability of the measurements on the same individual, being translated as the square root of the total variance excluding the variance between subjects. ${ }^{22,23}$ SEM is expressed by the same unit of measurement and was calculated using the equation below:

$$
E P M=\text { highest } S D * V(1-I C C)
$$

In addition, minimum detectable change (MDC), considered a measure of sensitivity that can be described as the smallest variation in the measurement that can be interpreted as real change, ${ }^{23}$ was calculated using the equation below:

$$
\mathrm{MDC}=1.96 \times \sqrt{ } 2 * \mathrm{SEM}
$$

\section{RESULTS}

Thirty-one subjects were evaluated-20 women and 11 men with an average age of $23.8( \pm 3.91)$ years, average body mass of 66.85 ( \pm 9.38$)$ kilograms, and average height of 1.68 ( \pm $0.06)$ meters. All were physically active and without any kind of pain or dysfunction of the shoulder joint. Of these, $96.77 \%$ were right-handed and $3.23 \%$ left-handed.

Table 1 presents the mean values, standard deviation, correlation, and SEM and MDC values for PhisioPlay and the isokinetic dynamometer for the dominant and non-dominant limbs at $45^{\circ}$.

Table 2 presents the mean values, standard deviation, correlation, and SEM and MDC values for PhisioPlay and the isokinetic dynamometer for the dominant and non-dominant limbs at $90^{\circ}$. To observe the behavior of the JPS according to the different variables (angular position, instruments, and laterality), the values of absolute difference (error, deviation) in relation to the target angle were polled according to these conditions for comparison by the Wilcoxon test and are presented in Table 3.

Table 1. Mean values and standard deviation, Intraclass Correlation Coefficient, standard error of measurement e minimal detectable change of the mean angulation and difference to the target (diff.) for dominant and non-dominant limbs at the

\begin{tabular}{|c|c|c|c|c|c|c|c|c|}
\hline SHOULDER & VARIABLE & ISO & PHY & ICC & ICC LEVEL & $95 \% \mathrm{Cl}$ & SEM & MDC \\
\hline \multirow{3}{*}{ DOMINANT } & $\begin{array}{l}\text { Mean angulation } \\
45^{\circ}\end{array}$ & $\begin{array}{l}45,60 \\
(3,10)\end{array}$ & $\begin{array}{l}50,08 \\
(3,64)\end{array}$ & 0,58 & MODERATE & $0,088-0,805$ & 2,36 & 6,10 \\
\hline & & & & & & & & \\
\hline & Diff. $45^{\circ}$ & $\begin{array}{c}3,49 \\
(2,13)\end{array}$ & $\begin{array}{c}5,28 \\
(3,33)\end{array}$ & 0,14 & LOW & $-0,826-0,597$ & 3,08 & 8,49 \\
\hline \multirow{3}{*}{ NON-DOMINAN } & $\begin{array}{l}\text { Mean angulation } \\
450\end{array}$ & $\begin{array}{l}45,96 \\
(4,64)\end{array}$ & $\begin{array}{l}50,39 \\
(3,71)\end{array}$ & 0,15 & LOW & $-0,817-0,599$ & 4,29 & 2,96 \\
\hline & & & & & & & & \\
\hline & Diff. $45^{\circ}$ & $\begin{array}{c}4,30 \\
(2,21)\end{array}$ & $\begin{array}{c}5,58 \\
(3,41)\end{array}$ & 0,25 & LOW & $-0,604-0,646$ & 4,68 & 5,86 \\
\hline
\end{tabular}
isokinetic dynamometer (ISO) and PhisioPlay (PHY) at $45^{\circ}$ 
Table 2. Mean values and standard deviation, Intraclass Correlation Coefficient, standard error of measurement e minimal detectable change of the mean angulation and difference to the target (diff.) for dominant and non-dominant limbs at the isokinetic dynamometer (ISO) and PhisioPlay (PHY) at $90^{\circ}$

\begin{tabular}{|c|c|c|c|c|c|c|c|c|}
\hline SHOULDER & VARIABLE & ISO & PHY & ICC & ICC LEVEL & $95 \%$ IC & SEM & MDC \\
\hline & $\begin{array}{l}\text { Mean angulation } \\
90^{\circ}\end{array}$ & $\begin{array}{l}89,54 \\
(2,76)\end{array}$ & $\begin{array}{l}92,36 \\
(4,09)\end{array}$ & 0,49 & MODERATE & $-0,081-0,762$ & 2,91 & 5,76 \\
\hline \multicolumn{9}{|l|}{ DOMINANT } \\
\hline & Diff. $90^{\circ}$ & $\begin{array}{c}2,97 \\
(1,33)\end{array}$ & $\begin{array}{c}3,28 \\
(2,85)\end{array}$ & 0,18 & LOW & $-0,771-0,621$ & 2,58 & 5,10 \\
\hline \multirow{2}{*}{ NON-DOMINAN } & $\begin{array}{l}\text { Mean angulation } \\
90 \%\end{array}$ & $\begin{array}{l}89,64 \\
(2,18)\end{array}$ & $\begin{array}{c}90,5 \\
(2,61)\end{array}$ & 0,51 & MODERATE & $-0,054-0,774$ & 1,82 & 3,61 \\
\hline & Diff. $90^{\circ}$ & $\begin{array}{c}2,90 \\
(1,33)\end{array}$ & $\begin{array}{c}2,14 \\
(1,55)\end{array}$ & 0,09 & LOW & - 0,977 - 0,577 & 1,48 & 2,93 \\
\hline
\end{tabular}

ICC: Intraclass correlation coefficient; 95\% IC: Confidence interval; SEM: Standard error of measurement; MDC: Minimal detectable change; Significance level at $95 \%(p<0,05)$

Table 3. Wilcoxon Test comparing absolute mean difference to the target angle values considering angular position, instruments, laterality or laterality associated to target angle

\begin{tabular}{|c|c|c|c|c|}
\hline VARIABLE & MEAN & SD & $n$ & $p$ \\
\hline \multicolumn{5}{|l|}{ ANGLE } \\
\hline $45^{\circ}$ & 5,17 & 3,2 & \multirow[b]{2}{*}{124} & \multirow[b]{2}{*}{$<0,001^{*}$} \\
\hline $90^{\circ}$ & 3,52 & 2,36 & & \\
\hline \multicolumn{5}{|l|}{ INSTRUMENT } \\
\hline PHISIOPLAY & 5,07 & 3,38 & \multirow[b]{2}{*}{124} & \multirow[b]{2}{*}{$<0,001^{*}$} \\
\hline ISOK. DINAMOMETER & 3,62 & 2,16 & & \\
\hline \multicolumn{5}{|l|}{ LATERALITY } \\
\hline DOMINANT & 4,25 & 2,83 & \multirow{2}{*}{62} & \multirow[b]{2}{*}{0,35} \\
\hline NON-DOMINANT & 4,44 & 3,06 & & \\
\hline \multicolumn{5}{|l|}{$45^{\circ}$} \\
\hline DOMINANT & 4,72 & 3,04 & \multirow[b]{2}{*}{62} & \multirow[b]{2}{*}{$0,017^{*}$} \\
\hline NON-DOMINANT & 5,61 & 3,31 & & \\
\hline \multicolumn{5}{|l|}{$90^{\circ}$} \\
\hline DOMINANT & 3,77 & 2,53 & \multirow[b]{2}{*}{62} & \multirow[b]{2}{*}{0,156} \\
\hline NON-DOMINANT & 2,27 & 2,18 & & \\
\hline
\end{tabular}

Significance level at $95 \%(p<0,05)$

\section{DISCUSSION}

Considering the importance of proprioception in maintaining joint stability and the need of accessible and easyto-use tools to assess shoulder JPS, this study sought to validate the PhisioPlay software for this purpose.

When comparing the two instruments, it was found that PhisioPlay correlated with the isokinetic dynamometer, which is considered a technologically advanced piece of equipment and possesses its own specific protocol for proprioceptive evaluation by JPS. However, the level of correlation between the instruments was more evident at $90^{\circ}$ of abduction for the mean values obtained for the dominant and non-dominant limbs.

No studies were found in which an isokinetic dynamometer was used to validate assessment instruments for shoulder JPS; studies undertaken to validate assessment instruments used other equipment and techniques as parameters. ${ }^{24,25}$ Ager et al. ${ }^{6}$ in a systematic review, reported the lack of validation studies of instruments to assess proprioceptive aspects of the shoulder joint and the lack of standardization of the proprioceptive assessment protocols.

In one of the few validation studies of instruments for the assessment of shoulder proprioception, the criteria for reliability and validity of the laser pointer, inclinometer, and goniometer were verified by comparison to a threedimensional motion capture system. ${ }^{24}$ Authors found strong correlation for the laser pointer and for the inclinometer at $55^{\circ}$ and $90^{\circ}$ of shoulder flexion. Also, strong and moderate correlations for the goniometer in the angular positions of $55^{\circ}$ and $90^{\circ}$ of flexion were found, respectively. The better results of these authors in comparison to the present research can be explained by the fact that in the study cited, variations of $10^{\circ}$ above or below the target angle were considered acceptable during the period of maintaining the position, and the authors evaluated not abduction but shoulder flexion. 
In another study, authors sought to verify the validity of an instrument for the assessment of JPS using a magnetic movement-tracking system as a comparison. However, the authors evaluated scapular movement during sustained $90^{\circ}$ shoulder abduction and found a better correlation for the nondominant limb. ${ }^{25}$ However, another study that compared shoulder JPS between dominant and non-dominant limbs found a difference between the sides only during the lowest angle of the tested protocol, which was $55^{\circ} .{ }^{16}$

This result is aligned with the findings of the present research, suggesting that angular positioning error is more affected by angulation (movement amplitude) than by lateral dominance. When comparing exclusively the differences in relation to the target angle between the dominant and nondominant limbs, the present study found no difference between left and right sides. However, when comparing in relation to the target angle, the difference between the dominant and non-dominant sides was found only at $45^{\circ}$ of movement.

More accurate JPS at mid and high ranges of angular amplitude was also described by other authors who compared the movement of the shoulder at different angles. ${ }^{24,26,27}$ This fact can be attributed to the greater activity of the muscletendon mechanoreceptors (Golgi tendon organs and muscle spindles) that occurs when there is greater muscle tension, in this case, by muscle contraction to perform the movement against gravity. ${ }^{28,29}$

Moreover, as movement progresses, other joints of the shoulder complex, in addition to the glenohumeral joint, start to act progressively..$^{30-32}$ Thus, all musculature, ligaments, and tendons involved contribute with proprioceptive information captured by the mechanoreceptors of these structures.

Comparing both instruments, greater repositioning errors were found with PhisioPlay. This is because, in the isokinetic dynamometer, the movement to be performed requires the subject to raise a bar that acts on the rotation axis of the device, which generates greater overload and consequently more intense muscle contraction.

Therefore, the muscle-tendon mechanoreceptors are more intensely stimulated in the isokinetic dynamometer, while in PhisioPlay, the overload is only the mass of the limb against gravity. The sense of force, which mixes the perception of weight with the intensity of muscle contraction, may also have contributed to the greater JPS accuracy. The torque on the joint requires greater muscle contraction intensity and has an effect on the accuracy of angular repositioning. ${ }^{33-35}$

SEM assesses the expected random error of the measurement ('noise' in the data), which may originate from the instrument, the evaluator, or the subject; that is, it may involve technological aspects, biological aspects, or even reflect changes in the subject's physical and mental states. ${ }^{22}$

SEM values varied from 2.36 to 4.29 at $45^{\circ}$ and from 1.48 to 2.91 at $90^{\circ}$, so it is possible to say that the measurement at $90^{\circ}$ showed less error (noise) than the measurement at $45^{\circ}$. The MDC value of $95 \%$ significance was calculated from EPM. MDC is a measure of sensitivity because, based upon it, in repeated measures, one can conclude whether the change observed in the value is real; thus, it is of great use in clinical practice. MDC values varied at $45^{\circ}$ from 4.68 to 8.49 , and at $90^{\circ}$ from 2.93 to 5.76 , which demonstrates that the sensitivity was greater at $90^{\circ} .14,23$

The present research has certain limitations, such as the impossibility of evaluating JPS on both instruments simultaneously (concurrent validity). This is because the subject was seated, and the structure of the isokinetic dynamometer in the background caused disturbance in the image capture by Kinect ${ }^{\circledR}$. As much as we tried to match the conditions of both tests, the differences between both methods were also a limiting factor, such as the fact that angular position is recorded in a single moment by the isokinetic dynamometer while dozens of records are acquired by PhisioPlay.

The isokinetic dynamometer test is performed sitting and with the subject's trunk stabilized, while in PhisioPlay, the test is performed standing, and trunk stabilization depends exclusively on the volunteer. Another difference between the two instruments concerns the overload on the shoulder joint during isokinetic dynamometer tests generated by the need to move the device arm (bar) against gravity, whereas PhisioPlay tests present no extra load.

Considering the importance of proprioception for joint stability during movement, there is a need for instruments that are capable of developing and evaluating this capacity during the rehabilitation process. Isokinetic dynamometers are one of these equipments, developed with high technology, equipped with a variety of programs and functionalities, and able to be applied with a range of possibilities.

Therefore, their high cost makes them available only in specialized centers, becoming very little accessible. Thus, the PhisioPlay software represents an affordable, portable, easy to use and easy to interpret results alternative resource, evidencing its clinical relevance for the rehabilitation process of patients with proprioceptive deficits.

\section{CONCLUSION}

The results obtained point to the construct validity of the PhisioPlay software for the evaluation of shoulder joint JPS at $45^{\circ}$ and $90^{\circ}$. However, the correlation between the instruments is stronger at $90^{\circ}$ of abduction of the dominant shoulder joint.

Considering the two instruments only, shoulder joint JPS errors were greater with PhisioPlay tests than with isokinetic dynamometer tests, regardless of other variables, such as dominant or non-dominant limb and target angle. Regarding dominant and non-dominant limbs only, there was no difference in the repositioning error, regardless of the instrument or target angle.

Comparing the difference in repositioning the shoulder joint at $45^{\circ}$ and $90^{\circ}$, regardless of dominant limb or nondominant limb and equipment, greater errors of repositioning were found at $45^{\circ}$. Observing the dominance of the limb associated with the target angle $\left(45^{\circ}\right.$ and $\left.90^{\circ}\right)$ and disregarding instruments, there were differences in shoulder JPS between the dominant and non-dominant limbs only at the target angle of $45^{\circ}$.

\section{ACKNOWLEDGEMENTS}

This study was financed in part by the Coordenação de Aperfeiçoamento de Pessoal de Nível Superior - Brasil (CAPES) - Finance Code 001 through the Postgraduate Program in 
Rehabilitation Science of the Universidade Federal de Alfenas UNIFAL.

\section{REFERENCES}

1. Riemann BL, Lephart SM. The sensorimotor system, part I: the physiologic basis of functional joint stability. J Athl Train. 2002;37(1):71-9.

2. Stillman Stillman BC. Making sense of proprioception: the meaning of proprioception, kinaesthesia and related terms. Physiother. 2002;88(11):667-76. Doi: https://doi.org/10.1016/S0031-9406(05)60109-5

3. Proske U. The role of muscle proprioceptors in human limb position sense: a hypothesis. J Anat. 2015;227(2):178-83. Doi: https://doi.org/10.1111/joa.12289

4. Goble DJ. Proprioceptive Acuity assessment via joint position matching: from basic science to general practice. Phys Ther. 2010;90(8):1176-84.

Doi: http://dx.doi.org/10.2522/ptj.20090399

5. Han J, Waddington G, Adams R, Anson J, Liu Y. Assessing proprioception: a critical review of methods. J Sport Heal Sci. 2016;5(1):80-90.

Doi: http://dx.doi.org/10.1016/j.jshs.2014.10.004

6. Ager AL, Roy JS, Roos M, Belley AF, Cools A, Hébert LJ. Shoulder proprioception: how is it measured and is it reliable? A systematic review. J Hand Ther. 2017;30(2):22131. Doi: http://dx.doi.org/10.1016/j.jht.2017.05.003

7. Clark NC, Röijezon U, Treleaven J. Proprioception in musculoskeletal rehabilitation. Part 2: clinical assessment and intervention. Man Ther. 2015;20(3):378-87. Doi: http://dx.doi.org/10.1016/j.math.2015.01.009

8. Hillier S, Immink M, Thewlis D. Assessing proprioception: a systematic review of possibilities. Neurorehabil Neural Repair. 2015;29(10):933-49. Doi: http://dx.doi.org/10.1177/1545968315573055

9. Matsen FA, Lauder A, Rector K, Keeling $\mathrm{P}$, Cherones AL. Measurement of active shoulder motion using the Kinect, a commercially available infrared position detection system. J Shoulder Elb Surg. 2016;25(2):216-23. Doi: http://dx.doi.org/10.1016/j.jse.2015.07.011

10. Saalfeld B, Pingel I, Wolf KH. Semi-Automatically Measuring Shoulders' Range of Motion - objective measurements with good reliability and accuracy. Stud Health Technol Inform. 2018;247:631-635. Doi: http://dx.doi.org/10.3233/978-1 61499-852-5-631

11. Soares JV, Carvalho LC, Bressan PA. PhysioPlay: um exergame para reabilitação física aplicando a interatividade do Kinect como biofeedback visual [Monografia]. Alfenas: Universidade Federal de Alfenas; 2012.

12. Oliveira RF, Carvalho LC, Bressan PA. Shoulderforce: um exergame para reabilitação física aplicando a interatividade do Kinect como biofeedback visual [Monografia]. Alfenas: Universidade Federal de Alfenas; 2015.

13. Marin LF, Bressan PA, Carvalho LC. PhysioPlay: um software para avaliação da amplitude de movimento e treinamento [Monografia]. Alfenas: Universidade Federal de Alfenas; 2017.
14. Edouard P, Gasq D, Calmels P, Degache F. Sensorimotor control deficiency in recurrent anterior shoulder instability assessed with a stabilometric force platform. J Shoulder Elb Surg. 2014;23(3):355-60. Doi: https://dx.doi.org/10.1016/j.jse.2013.06.005

15. Fortier S, Basset FA. The effects of exercise on limb proprioceptive signals. J Electromyogr Kinesiol. 2012;22(6):795-802.

Doi: https://dx.doi.org/10.1016/j.jelekin.2012.04.001

16. Echalier C, Uhring J, Ritter J, Rey PB, Jardin E, Rochet S, et al. Variability of shoulder girdle proprioception in 44 healthy volunteers. Orthop Traumatol Surg Res. 2019;105(5):825-9. Doi: https://dx.doi.org/10.1016/j.otsr.2019.01.019

17. Findlater SE, Hawe RL, Semrau JA, Kenzie JM, Yu AY, Scott SH, et al. Lesion locations associated with persistent proprioceptive impairment in the upper limbs after stroke. Neurolmage Clin. 2018;20(August):955-71. Doi: https://dx.doi.org/10.1016/i.nicl.2018.10.003

18. Matsudo S, Araújo T, Matsudo V, Andrade D, Andrade E, Oliveira LC, et al. Questionário Internacional de Atividade Física (IPAQ): estupo de validade e reprodutibilidade no Brasil. Rev Bras Ativ Fis Saúde. 2001;6(2):5-18. Doi: https://dx.doi.org/10.12820/rbafs.v.6n2p5-18

19. Martins J, Napoles BV, Hoffman CB, Oliveira AS. Versão brasileira do Shoulder Pain and Disability Index: tradução, adaptação cultural e confiabilidade. Rev Bras Fisioter. 2010;14(6):527-36. Doi: http://dx.doi.org/10.1590/S1413$\underline{35552010000600012}$

20. Terwee $C B$, Bot SDM, de Boer MR, van der Windt DAWM, Knol DL, Dekker J, et al. Quality criteria were proposed for measurement properties of health status questionnaires. J Clin Epidemiol. 2007;60(1):34-42. Doi: https://dx.doi.org/10.1016/j.jclinepi.2006.03.012

21. Field A. Descobrindo a estatística usando o SPSS. 2 ed. Porto Alegre: Artmed; 2009.

22. Hopkins WG. Measures of reliability in sports medicine and science. Sport Med. 2000;30(1):1-15. Doi: https://dx.doi.org/10.2165/00007256-200030010-00001

23. Beckerman $\mathrm{H}$, Roebroeck ME, Lankhorst GJ, Becher JG, Bezemer PD, Verbeek AL. Smallest real difference, a link between reproducibility and responsiveness. Qual Life Res. 2001;10(7):571-8.

Doi: https://dx.doi.org/10.1023/a:1013138911638

24. Vafadar AK, Côté JN, Archambault PS. Interrater and intrarater reliability and validity of 3 measurement methods for shoulder-position sense. J Sport Rehabil.; 2016;25(1):2014-0309. https://dx.doi.org/10.1123/isr.2014-0309

25. Deng HR, Shih YF. Test validity and intra-rater reliability in the measurement of scapular position sense in asymptomatic young adults. Man Ther. 2015;20(3):503-7. Doi: https://dx.doi.org/10.1016/i.math.2015.02.002

26. Suprak DN, Sahlberg JD, Chalmers GR, Cunningham W. Shoulder elevation affects joint position sense and muscle activation differently in upright and supine body orientations. Hum Mov Sci. 2016;46:148-58. Doi: https://dx.doi.org/10.1016/j.humov.2016.01.008 
27. Diefenbach BJ, Lipps DB. Quantifying the three-dimensional joint position sense of the shoulder. Hum Mov Sci. 2019;67:102508.

Doi: https://dx.doi.org/10.1016/i.humov.2019.102508

28. Safran MR, Borsa PA, Lephart SM, Fu FH, Warner JJ. Shoulder proprioception in baseball pitchers. J Shoulder Elbow Surg. 2001;10(5):438-44.

Doi:

https://dx.doi.org/10.1067/mse.2001.118004

29. Suprak DN. Shoulder joint position sense is not enhanced at end range in an unconstrained task. Hum Mov Sci. 2011;30(3):424-35.

Doi: https://dx.doi.org/10.1016/j.humov.2011.02.003

30. Hess SA. Functional stability of the glenohumeral joint. Man Ther. 2000;5(2):63-71. Doi: https://dx.doi.org/10.1054/math.2000.0241

31. Yanagawa T, Goodwin CJ, Shelburne KB, Giphart JE, Torry MR, Pandy MG. Contributions of the individual muscles of the shoulder to glenohumeral joint stability during abduction. J Biomech Eng. 2008;130(2):021024. Doi: https://dx.doi.org/10.1115/1.2903422
32. Hurov J. Anatomy and mechanics of the shoulder: review of current concepts. J Hand Ther. 2009;22(4):328-43. Doi: https://dx.doi.org/10.1016/i.jht.2009.05.002

33. Vafadar AK, Côté JN, Archambault PS. Sex differences in the shoulder joint position sense acuity: a cross-sectional study. BMC Musculoskelet Disord. 2015;16:273. Doi: https://dx.doi.org/0.1186/s12891-015-0731-y

34. Proske $U$, Allen T. The neural basis of the senses of effort, force and heaviness. Exp Brain Res. 2019;237(3):589-99. Doi: https://dx.doi.org/10.1007/s00221-018-5460-7

35. Gandevia SC. Proprioception, tensegrity, and motor control. J Mot Behav. 2014;46(3):199-201. Doi: https://dx.doi.org/10.1080/00222895.2014.883807 